\title{
Die Physiopraxis der Zukunft
}

\author{
FIBO PRÄSENTIERT Die FIBO ist die weltweit führende Messe für Fitness, \\ Wellness und Gesundheit. Neu in diesem Jahr: Halle 7 widmet sich aus- \\ schließlich dem Gesundheitsmarkt. Ein Schmankerl darin ist die „physiopraxis \\ 2020“. Sie gibt Anregungen für eine zukunftsorientierte Praxisgestaltung \\ und -ausstattung, die Patienten und Kunden gerecht wird.
}

\section{A} us Patienten werden Kunden - darin liegt die Zukunft. Therapeuten wünschen sich zudem, dass Patienten in nicht allzu weiter Ferne direkt zur Physiotherapie kommen können. Patienten wünschen sich die Besserung ihrer Symptome. Physiotherapeuten bieten in der Regel mehr: Nähe, Zeit, ein Ohr, Beratung, Hilfe zur Selbsthilfe. Und das fast immer in liebevoll eingerichteten Praxen. Kunden hingegen erwarten noch ein bisschen mehr. Kunden sehen in Therapeuten einen Geschäftspartner: Therapeuten bietet ihnen etwas an, wofür es sich lohnt, in die eigene Tasche zu greifen. Die Kunden wissen, wenn sie den Therapeuten brauchen, ist er für sie da.

Kundenbindung ist in der modernen Physiotherapie kein Fremdwort mehr und schon gar

1.

\section{FIBO UND FIBOMED}

\section{Infos und Anmeldung}

Die FIBO ist vom 3. bis 6. April 2014 in Köln. Der physiotag findet am 5. April 2014 im Kongresszentrum der Messe Köln statt. Die Karte dafür kostet 69 Euro und kann online bestellt werden unter www.fibo.de/karten. Die Aussteller zum Gesundheitsmarkt präsentieren sich in Halle 7. Die Ausstellerliste steht unter www.fibo-med.de.

nicht anrüchig. Es geht nicht um Abhängigkeit. Es geht um Angebote, die auch von gesunden Menschen genutzt werden, die für ihre Bewegung, ihr Training und ihre aktive Erholung professionelle Anleitung suchen.

Die „physiopraxis 2020“ auf der FIBO ist auf Patienten und Kunden eingestellt. Auf einer besonderen Aktionsfläche der Halle 7 können Therapeuten durch die Physiopraxis der Zukunft schlendern und sich inspirieren lassen. Bereits der Rezeptionsbereich strahlt Professionalität aus und das Gefühl „Hier fühle ich mich wohl“. Die Räume geben Ideen zur Gestaltung und Ausstattung, vom Einzelbehandlungsraum bis zur KGG-Ausstattung und zum Fitnessparcours, in dem Patienten und Kunden selbst trainieren können.

Rosi Haarer-Becker und Uwe Harste

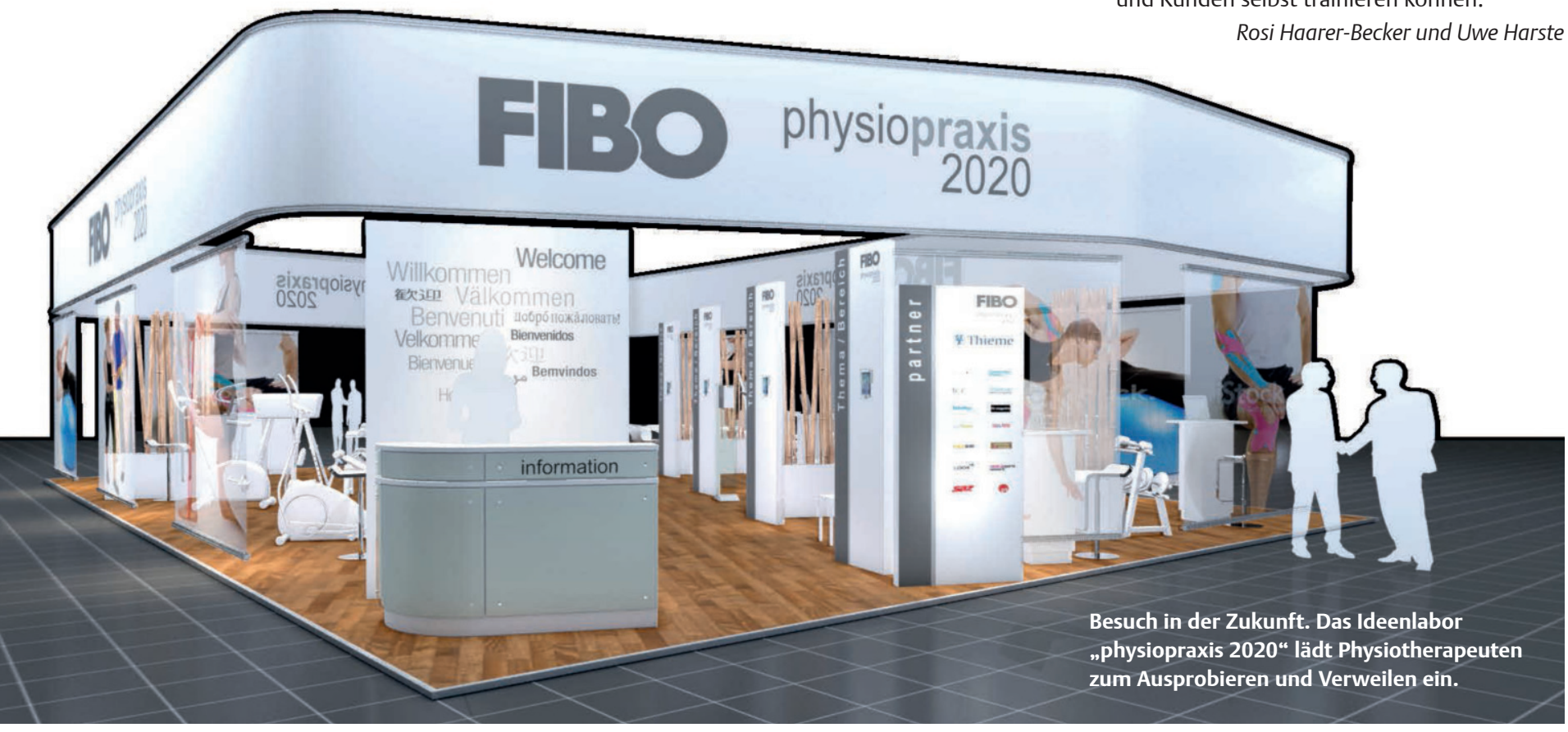

